\title{
Electronic Toll Collection System based on Radio Frequency Identification System
}

\author{
Raed Abdulla, Aden Abdillahi, Maythem K. Abbas \\ School of Engineering, Asia Pacific University of Technology and Innovation (APU), \\ Technology Park Malaysia, Bukit Jalil, Kuala Lumpur 57000, Malaysia
}

\begin{tabular}{l} 
Article Info \\
\hline Article history: \\
Received Feb 13, 2018 \\
Revised Apr 21, 2018 \\
Accepted Apr 27, 2018 \\
\hline
\end{tabular}

Keyword:

Electronic toll collection Internet of things Radio frequency identification Vehicles passing

\begin{abstract}
This papaer entitled electronic toll collection system based on Radio Frequncy Identification System explained in detail based on current issue at toll collection system. There are some obstacles faced every day where the users spent their valuable time in queue at tollgate due to traffic congestion as well as using traditional manual method in most existing toll ETC system to collect toll from road users. Besides that, the barrier design where each vehicle stop waiting until barrier lift which consider source of time delay. To tackle stated problems, an electronic toll collection system is proposed which based on RFID technology. The integrated system consists of two main sections, electronic sides where all input data received from while database management office is where all necessary information stored. To compare the current ETC system, in this research elaborated internet of things where all data transmit through cloud and then to the main office in real time. Not only that, there is some enhancement based on barrier design where, gate is remained open for all vehicles with sufficient tags without requiring to stop to eliminate time delay.By check system throughput compare to existing toll systems, various tests have been carried out in different method where proposed system throughput much higher percentage the current system.
\end{abstract}

Copyright (C) 2018 Institute of Advanced Engineering and Science. All rights reserved.

\section{Corresponding Author:}

Raed Abdulla,

School of Engineering,

Asia Pacific University of Technology and Innovation (APU),

Technology Park Malaysia, Bukit Jalil, Kuala Lumpur 57000, Malaysia.

Email: dr.raed@apu.edu.m

\section{INTRODUCTION}

In recent days, transportation plays very important rule in development of human life and considered non-independent part in modern society that leads to make a potential change in the way of living. Transportation infrastructures are of crucial importance to the development of a country [1]. Despite of that importance, there many challenge due to growing population in worldwide, accompanied increasing number of road users correspondingly. Besides that, the high demand of transportation, concomitant a huge traffic congestion at toll booth which affect environment and human life due to fuel emission. To facilitate vehicle passing at toll gate, electronic toll collection system proposed which is the latest technology that enabling tolls to be collected from road users automatically without human interaction to eliminate time delay. Current ETC system consist of four main components which are Automatic vehicle identification used to check vehicle eligibility and automatic vehicle classification designed to assort type of the car in order charge different fare of transaction process. Eventually, violation enforcement system is equipped with a highquality camera capable to record all necessary information about the violators. In today's Electronic Toll Collection system has shown to advantage in fact feasible and financially attractive in modern society to facilitate users by collecting tolls electronically in highway without delay. 
Due to the nature of the RFID technology, which applied in locating and tracking objects, RFID has been recently applied to many location identification systems to detect the presence of tagged objects and/or people [2]. RFID offers advantages of non-touch identification, long-distance communication, working in a variety of harsh environments and that can read hundreds tags at a time [3]. Internet of things (IOT) connects all goods with internet through information sensing devices like radio frequency identification (RFID) for information exchange and intelligent identification, positioning, tracking, monitoring and management of goods [4]. Most of ETC system sharing same method with different technologies that enabling to identify whether the vehicles passing through the toll gate are enrolled and alerting those who not eligible using various technologies such as radio frequency identification (RFID), automatic number plate recognition and optical character recognition. Consequently, many researchers are dealing to enhance existing electronic toll collection to get rid of the delay on toll roads and to improve user safety as well as environmental quality.

In [5], the authors presented solution based on automatic toll collection system using RFID technology to overcome the traffic congestion problem at toll booth. The RFID reader is designed to broadcast waves to specific direction when vehicle approaches to the toll gate within the coverage zone, reader extract information from the tag which placed on the windscreen of the vehicles.

After authentication process system, able to detected fare from user's account which linked to their tag and recipe details send to users by SMS through registered phone number. The proposed system is highly securely and efficiently compare to existing manual toll collection system and provide highly reliable data collection. However, the throughput of the car passing at toll booth is low due to reducing the speed of the vehicles passing in order the reader able to detect tag information due to barrier which closing and opening all the time same as a classic method used most toll plaza which lead time delay.

In [6], the authors proposed electronic toll collection system using RFID, GPS and GSM. Based on the researcher's proposal the RFID tag used to identify the vehicles at entry and out of the road. When the vehicle enters at the start point of the road, the car information will be registered as well. its position is exhibited by GPS from the satellite to measure the latitude, longitude and speed then send information to database center.

The authors classified the authentication of the vehicles into two major conditions, Verification and validation process. If the car authenticated, and account balance is sufficient then fare will be calculated based on distance as well as receipt will be send to registered number by SMS. If the vehicle is not registered it classified as violator and alert will be send to police and action will be taken by authority. The proposed system is $15 \%$ much faster than the existing automatic toll collection system due to its accuracy of reducing vehicles congestion at tollgate. However, the accuracy of the system is low due to error data registration at entry point. Besides that, second limitation of the system, no barrier where violators can skype without stopped.

Because reliable, sufficiently small and adequately low cost RFID tags can nowbe built, the reputation of RFIDs has lately been on the increase [7]. In [8], the author researchers presented a new system automatic toll collection system using RFID and E-Pass tag which stored all necessary information of the car and the owner details. A unique ID is only attainable to use one vehicle only and they mention also that, the car owner is required to open an account for transection propose. This system, whenever the vehicle approach to the toll gate, the RFID reader extract data from tag which contain unique information and then reader send information database to check whether the car is eligible for toll payment by checking the registration, account.

If the user's account is sufficient that mean is eligible then barrier will be lift to let the car pass through. If amount is not sufficient, then the user required to pay toll manually otherwise an appropriate action will be taken by toll authority against defaulters.

Some results have been conducted by transferring data from electronic side direct to main database as well as verifying the vehicle eligibility. The limitation of this system also share same issue as the previous paper which concern traffic congestion due to system throughput.

In [9], the authors proposed an automatic plate number recognition system using optical character recognition (OCR) to authenticate vehicle by recognizing its plate number. In this research, whenever vehicle approach near toll gate, its plate number will be captured by high definition camera. On top of that, the captured image will be send to database to compare existing information that already stored in the data base and authentication process will be held. The condition if the vehicle is authenticated and the account balance is sufficient the barrier will be left. Otherwise, system will be classified the car under violation enforcement.

The advantage of this system is not required tag for users and the reader as long as it based on image processing only need high definition camera to capture a suitable image as well the plate number and car owner's information should store into database to compare.The gap identified in this system is effecting weather so that, it will be difficult to capture plate number and thus authentication process will be difficult. 
In [10], the authors proposed automatic vehicle identification using ANPR technology which enabled to captured image by the camera such as plate number and store into database to compare existing numbers. Besides that, the camera is active by infrared to enable to capture the image from plate number. When the fee is detected, the car owner will receive SMS displaying toll details and remaining balance.

The proposed system conducted some results by sending receipt to vehicle owner by SMS through registered number. Besides that, system enable to authenticate vehicles by capturing their plate number and comparing existing numbers in the database.The limitation of the system is that camera designed to capture vehicles plate numbers is effected by weather that leads to fail camera to capture plate number hence whole system will be affected.

In [11], the authors proposed an automatic toll collection system using NFC which used to control traffic congestion as well as to detect toll automatically. Based on researchers idea, this system will enhance the toll collection method without required vehicle to stop. By doing that it will help to reduce pollution and fuel consumption. Not only that, the system is designed to detect the stolen vehicles and informing to police by authenticating the vehicle eligibility during passing at toll gate. Not only that, the system interface that enable the user to log and modify his/her information and type of vehicles. The NFC tag is linked to user's account that already registered to detect toll. However, there are some condition to check enrollment of the users. For example, If the vehicle is stolen, then user should have complained to toll authority online. When customer complaining is received then authority will take action to deactivate users account and thus any time stolen vehicle pass any local toll plaza, system will detect by comparing stolen car information. If the algorithm is matched the will send SMS alert to nearest police and automatically barrier will close.

In this research, electronic toll collection system based on RFID and internet of things (IoT) is proposed to increase system throughput at toll gate entrance. The proposed system consist two main systems integrated together. The RFID (reader \& tag) system designed to receive input data from vehicles tags where reader extract information from tags and send to Arduino Yun board. Yun board built Wi-Fi capability and thus received that transmit to the main management office through cloud. Not only that, the barrier design is adjusted where the gate remains opening for all legal vehicles, only close when vehicle with insufficient tag or unregistered approach to the toll booth.

\section{RESEARCH METHOD}

The proposed design system consists two main parts. Foremost, electronic toll collection system that composed vehicle classification, identification and violation system. Subsequent, the electronic toll collection management system.

Figure 1 shows the proposed electronic toll collection system using RFID technology. The tag will be stored all necessary information such as vehicle owner, plate number, register number and linked bank account. In addition, the cars owners also required to create bank account which will be linked to their tags to detect fee electronically when in needed to use. Therefore, whenever the vehicle approach toward toll gate within the RFID reader coverage that designed to propagate the waves to specific direction where in coming vehicle located. To identify the vehicle coming into toll gate, the RFID reader will broadcast signal toward the tag which placed on windscreen of the vehicles. The tag will response, within milliseconds and data received from the tag will be sent to database to compare the existing information that already stored in database.

As illustrate the Figure 1 when the car proceeds towards the gate, the system will check the vehicle tag for authentication to avoid any violation. In this case, there are two conditions that required to take into consideration. Either, vehicle shows its tag or without tag. If the coming vehicle escorted its tags, then the system will check linked account balance to detected tolls. If account balance is sufficient then fare will be calculated and fee will be detected from his/her account. The receipt details and all necessary information will be send to owner through SMS. Likewise, if account funds not sufficient the wage will be send to possessor informing to pay within seven days.

On condition that, if car owner does not provide his unique tag, the barrier will be closed automatically and will be classified as violator. In this case, also there are two possibilities, either the vehicle owner doesn't have a unique tag or vehicle is stolen. After verification if owner shows his proof then owner will be asked pay tolls as well as provided tag next time otherwise action will be taken against him/her. In case driver fail to show any proof of ownership, then information will be sent to police and action will be taken by authority.

Figure 2 shows administration section where the user information and their details can be added, updated and deleted. To login this system, authentication is required where administrator need to login using his/her username and password. In this case, system will verify username and password by checking from the database and then comparing them for security purposes. If the username and password are matched, then the 
administrator will access to the system and has a full authority to add new members and remove as well. As mentioned in Figure 1, whenever users buy a car is required to have a smart tag too which stored all their necessary information. So, the administrator can register the new members as well as update their information when is need.

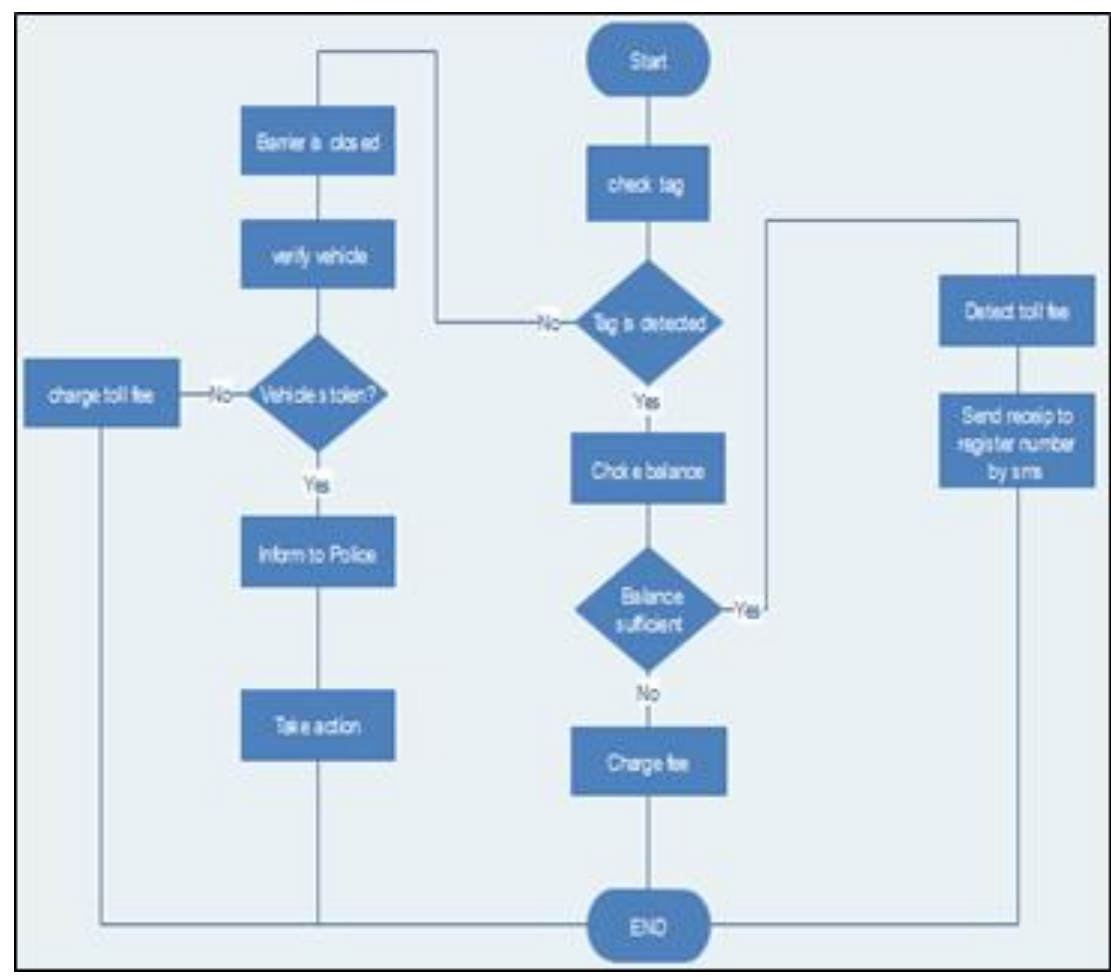

Figure 1. Proposed system flowchart for RFID

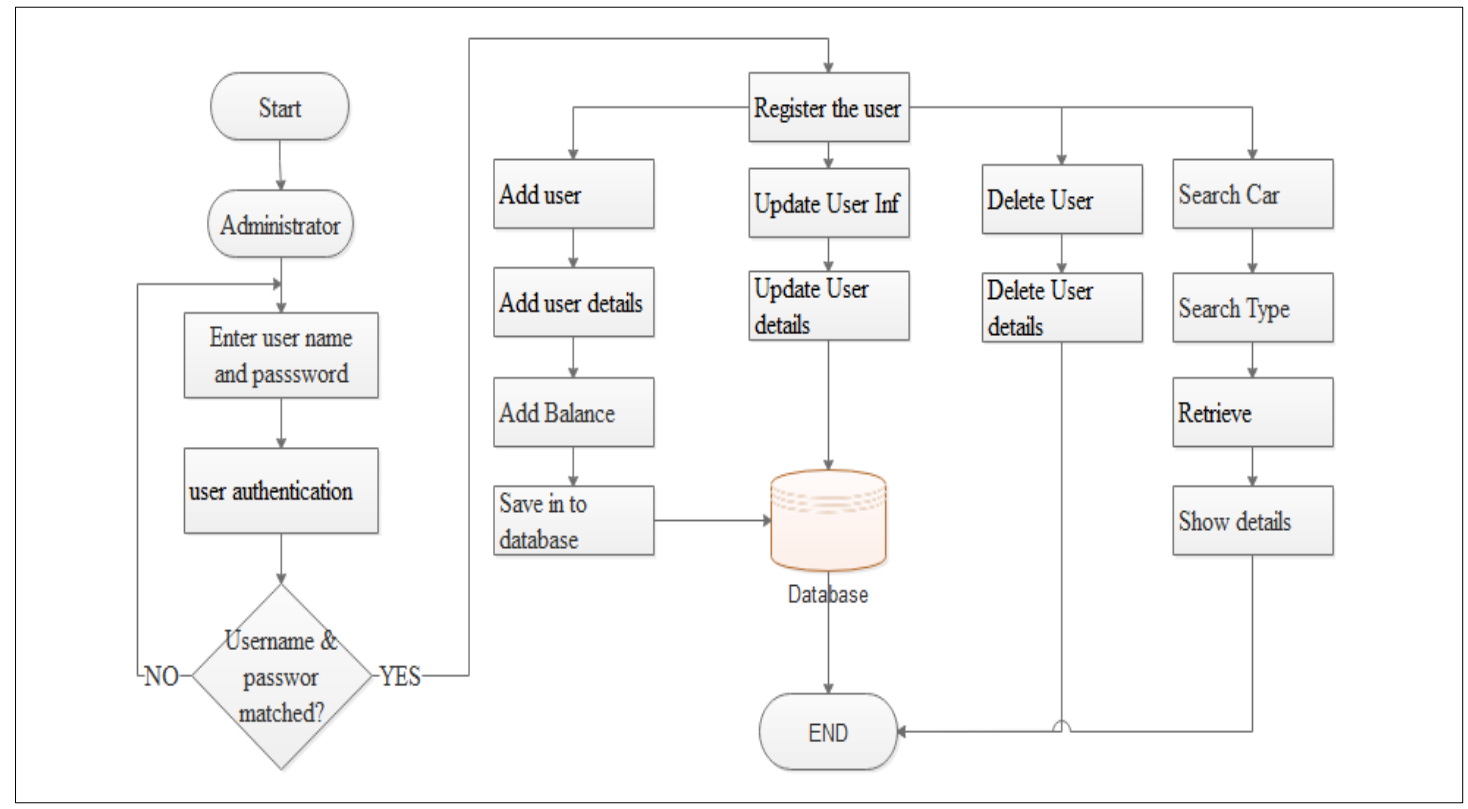

Figure 2. Proposed system flowchart for management section 


\section{SYSTEM IMPLEMENTATION}

The proposed system consists of four main subsections as illustrated in Figure 3 which is block diagram of the research to represent both systems integrated together. The electronic sides, tags used as an input when vehicles pass through gate where reader extract data from the tags then send to Arduino Yun. The Arduino built internet capability so that all data can be transmit to the cloud and then to the user as well as to the main office in real time.

RFID system consist tags, RFID reader, Arduino Yun board and management office which received data from RFID system as well as storing all received data. The RFID reader is composed of an antenna coil which capable to generate an electromagnetic field. When the tags get approach within coverage of the reader so that, tags can extract transmitted information from the reader and resend the message back to reader and then reader will transmit data to Arduino Yun. The Arduino Yun is built with Wi-Fi module and then easily all information will send to cloud and to the main office.

Figure 4 shows the circuit that consist of Arduino Yun broad which built Wi-Fi capability and ultrasonic sensor that used to classify types of the vehicles by measuring vehicle height. Besides that, the LCD displayed input information from the tags and RFID reader used to read and extract data from the tags. The three-different color of LEDs indicate three different conditions.

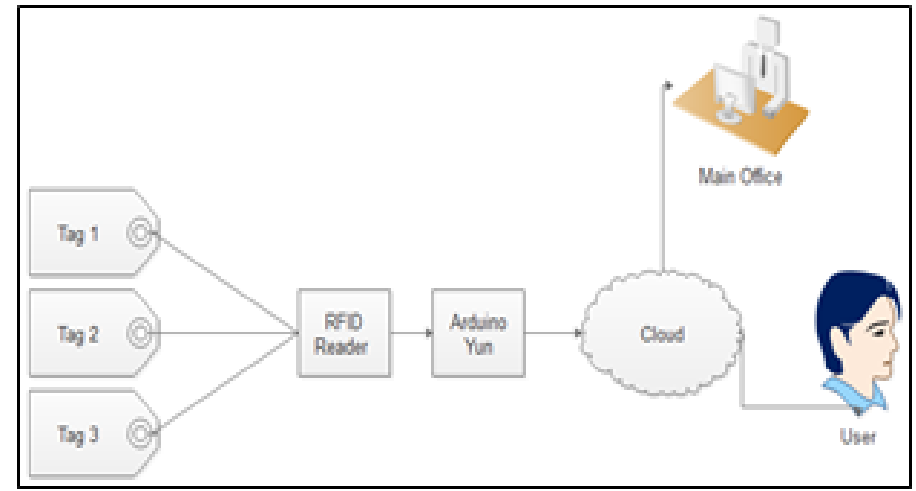

Figure 3. System block diagram

Green led blink when any vehicle with valid tag pass through gate as well as the yellow led blink when vehicle with insufficient tag cross through the toll booth. Besides that, red led blink when invalid or unregistered vehicle approach toward the gate and thus, the gate will be closed automatically by servo motor and the buzzer used to alert.

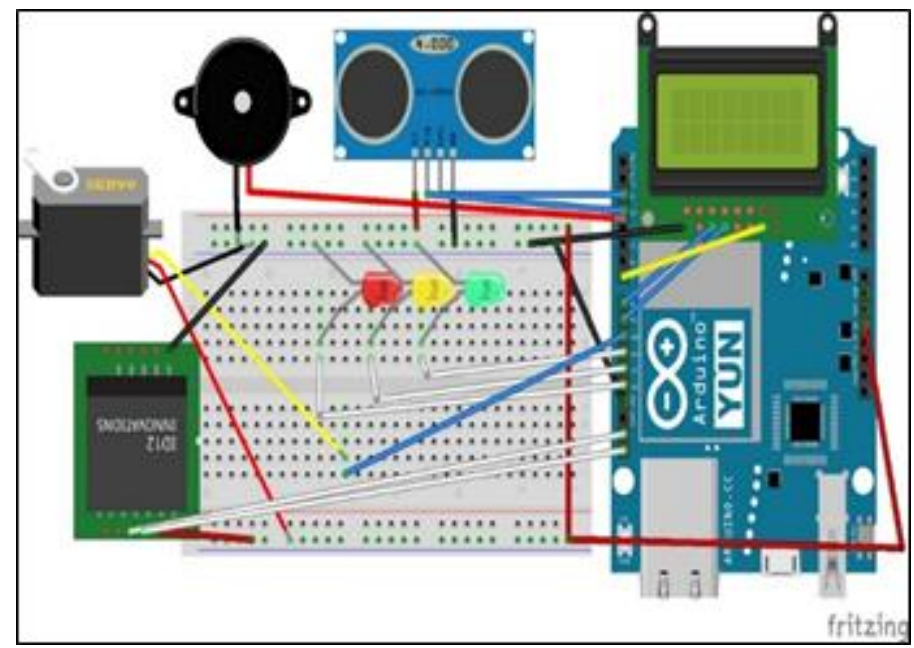

Figure 4. Circuit connection 


\section{RESULTS AND ANALYSIS}

In this section based on system performance. To test the system, will be focused on throughput performance by using comparison between two different methods to select the best result. First testing, based on open and close barrier when vehicles proceeding toward the gate. This method is same as the existing toll plaza where the barrier is lifting and closing during the vehicles passing through the toll booth. The second method based on new technique which never use in any toll plaza. This method, gate remaining open for all legal vehicles without stopping car passing or vehicle with valid tags. This method, the gate only stop vehicles with invalid tag or unregistered.

\subsection{First method}

To carry out the test, a toy car is prepared attached with rfid tag to represent as a vehicle. To calculate time delay, a timer is prepared and starts recording when toy car proceeded to the gate to determine throughput of the system per hour. When a toy car approached toward the gate, the barrier is closed to check vehicle eligibility requirements same as existing toll plaza so that, it required to wait barrier to lift at least few seconds and second car also follow same procedure. In this test, only one line is considered for testing purpose. The time taking when vehicle process into gate until it passed through is recorded 15 seconds.

To check system throughput, it required to determine number vehicles that can pass through the line within an hour. Each vehicle wasted 15 seconds during process at toll booth. To calculate number of vehicle can pass through gate per hour by dividing $3600 \div 15$ that gives 240 which mean 240 vehicles can pass through a single line per hour. In same procedures, the number of car passing single line per day can be calculated by multiplying number of vehicle pass per hour by 24 hours $240 \times 24=5760$ vehicles as well as the number of vehicle that can cross at toll booth per year also can be determine by multiplying by number of vehicle that passing through the gate per day by 30 days and 12 months of the year $5760 \times 30 \times 12=2073600$ vehicle per year. Figure 5 shows throughput of the system per hour, day and year. As illustrate figure, it can be seen obviously, that, system capacity per hour, day and year where 240 vehicles can pass through single per hour line and 5760 vehicles every day. In this method, system accommodate 207360 vehicles per year. This percentage is quite a lot, however due to increasing demand of transportation nowadays may not tackle to reduce traffic congestion at toll booth.

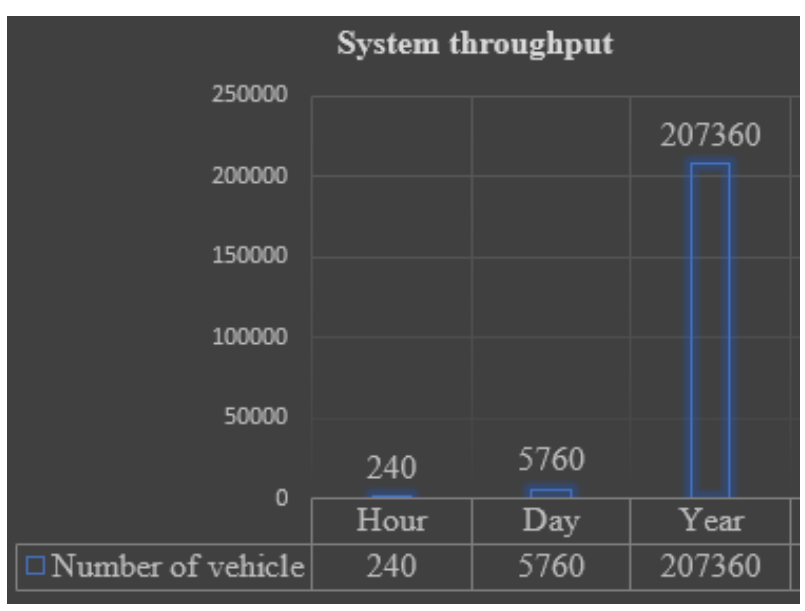

Figure 5. System throughput for first method

\subsection{Second method}

The procedures of this test are same as the first method, the only different is interval time which depend on the barrier design. In this case, also a toy car is presented which attached a RFID tag to represent as a vehicle. Timer also is set to determine the throughput of the system per hour. When a toy car approached toward the gate, system check eligibility of the tag where all vehicles with valid tags can pass through the gate without stopping. In this system, gate remains open for all the time for all vehicle with valid tags. Only gate will be closed when vehicle with invalid tag or unregistered proceed to pass through the booth by then barrier automatically close to stop illegal vehicle. In this method, time taking when vehicle proceed into gate until it passed through the gate is recorded 6 seconds experimentally.

To check system throughput, it need to determine number vehicles that can pass through that line within an hour. For this method, each vehicle reduce speed during process, recorded time is 6 second 
approximately. To calculate the system throughput per hour by dividing $3600 \div 6=600$ which means 600 vehicles can pass through a single line per hour as well as number of the car passing a single line per day can be calculate $600 \times 24=14400$ vehicles. In same procedure, the number of vehicle can cross at booth line per year is $14400 \times 30 \times 12=5184000$ vehicle per year.Figure 6 shows throughput of the system per hour, day and year As illustrate figure, it can be seen obviously, that, system capacity throughput per hour, day and year where 600 vehicles can pass through single line and 14400 vehicles every day. In this method, system accommodate 518400 vehicles per year. Compare to first method visibly the throughput of this method is more effective unlike first method.

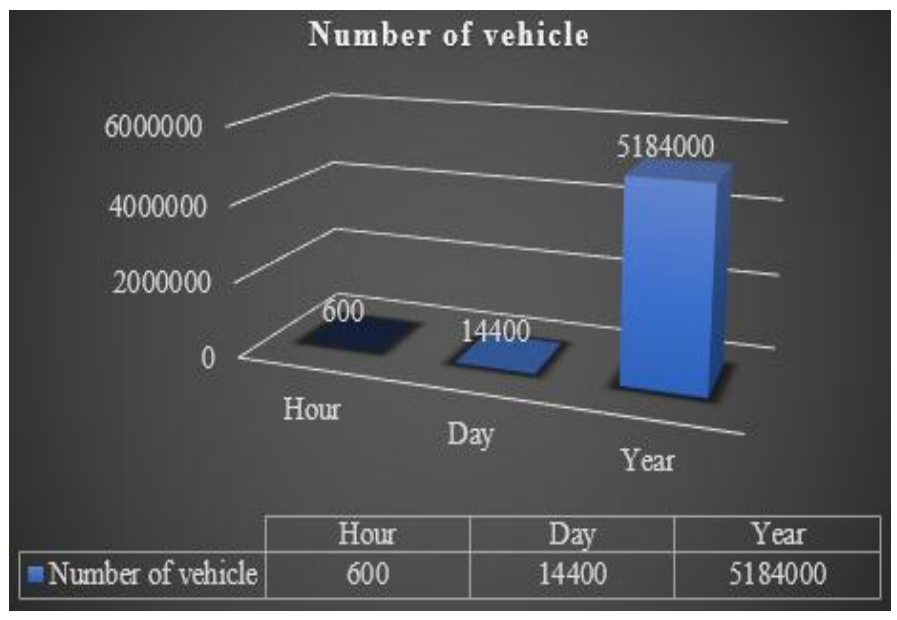

Figure 6. System throughput for second method

Figure 7 shows the comparison between throughputs of the two-different method that discussed above. As illustrated the figure throughput of the second method doubtless high compare to first method where the capacity throughput of second method is $71 \%$ unlike first method which only accommodate $29 \%$ per year. Thus, without doubt can say that second method is suitable to tackle traffic congestion problems which occur at toll gate.

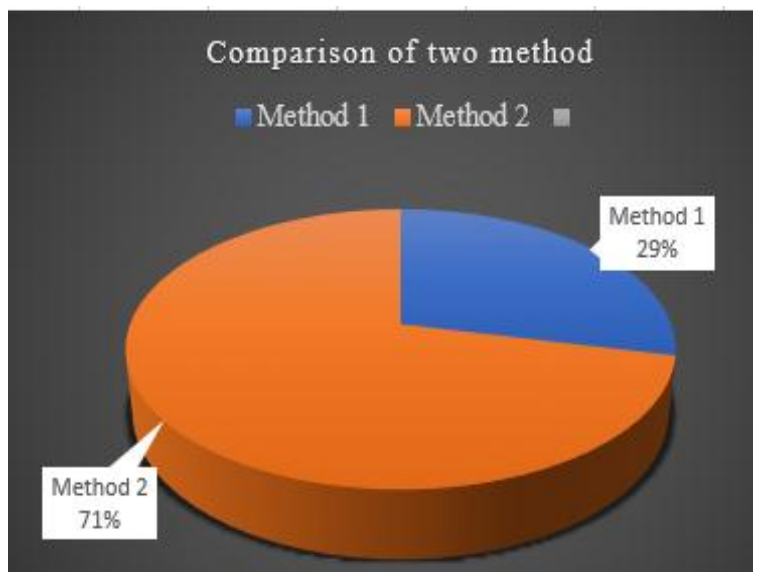

Figure 7. Comparison of system throughput for both method

\section{CONCLUSION}

The purpose of the research was designing an integrated electronic toll collection system using RFID technology and (IoT) to connect entire system with office database in real time. The integration of the system is enhanced by elaborating existing system with (IoT) to transmitting data received from RFID 
system and send to the main office in real time through cloud. Based on results obtained, the objective have been achieved in line with required output result of the system.

Some alteration has been done in barrier design. Unlike current method where all existing toll plaza barrier operate. To achieve that object, barrier position is changed as well as programed. The gate remains open for all vehicle with valid tags while it close automatically when vehicle with invalid tag or unregistered vehicle pass though gate. The software and prototype are accurately integrated and displayed all information as per presumption. Eventually, to store information a database is created along side with the codes of the all activities of the system.

\section{REFERENCES}

[1] Wang D, Li B, Li J, Li C, Wang L, "Research on the Public Transport Network Based on Complex Network", Indonesian Journal of Electrical Engineering and Computer Science, 2014, vol. 12, no. 6, pp. 4833-4839.

[2] Abdulla R, "A conceptual study of long range active RFID system for reliable data communication", In Frontiers of Communications, Networks and Applications (ICFCNA 2014-Malaysia), International Conference on IET, 2014, pp. 1-6.

[3] Deng J, "Architecture design of the vehicle tracking system based on RFID”, Indonesian Journal of Electrical Engineering and Computer Science, 2013, vol. 11, no. 6, pp. 2997-3004.

[4] Bing X, "Key Internet of Things Technology and Application Research", Indonesian Journal of Electrical Engineering and Computer Science, Jul 2014, vol. 12, no. 7, pp. 5599-5602.

[5] Salunke P, Malle P, Datir K, Dukale J, "Automated toll collection system using RFID”, Journal of Computer Engineering, 2013, vol. 9, no. 2, pp. 61-66.

[6] Kanthi, K., Dontabhaktuni, J., Jail, S, "Electronic Toll Collection System For Billing Using Wireless Communication", International Journal of Advanced Engineering Research and Science (IJAERS), 2013, vol. 1, no. 5, pp. 5-7.

[7] Abdulla, R. and Ismail, W., 2015, "Active RFID System with Embedded Wireless Sensor Network for Reliable Data Communication”, Technological Breakthroughs in Modern Wireless Sensor Applications, 2015, pp. 83-108.

[8] Salunke P, Malle P, Datir K, Dukale J, “Automated toll collection system using RFID”, Journal of Computer Engineering, 2013, vol. 9, no. 2, pp. 61-66.

[9] Karande MS, Dahotre AA, Malushte RA, Palve A, "Number Plate Recognition System using OCR for Automatic Toll Collection", International Journal of Science Technology \& Engineering, 2016, vol. 2, no. 10, pp. 3-6.

[10] Final MC, "Electronic Toll Collection System for Efficient Traffic Control System using ANPR", International Journal of Computing and Technology, vol. 1, no. 2, pp. 106-113, Mar 2014.

[11] Bharambe S, Kumbhar P, Patil P, Sawant K, "Automated Toll Collection System Using NFC And Theft Vehicle Detection”, International Journal of Computer International Journal Of Engineering And Computer Science, 2016, vol. 5, no. 4, pp. 16107-16110.

\section{BIOGRAPHIES OF AUTHORS}

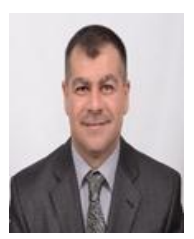

Dr. Raed Mohammed Taher Abdulla received the Bachelor's degree in Electrical engineering from AL-Mustansiria University, Baghdad, Iraq in 1997, the Master degree in Electronic Systems Design Engineering from Universiti Sains Malaysia, Malaysia in 2008 and he received his $\mathrm{PhD}$ in Wireless and Mobile Systems from Universiti Sains Malaysia, Malaysia in 2012. He is currently a Senior Lecturer at the School of Engineering, Asia Pacific University of Technology and innovation (APU) in Bukit Jalil, Kuala Lumbur, Malaysia. He has contributed in research and in the areas of Radio Frequency Identification (RFID) and Wireless Sensor Network (WSN). His research output was translated to numbers of awards and publications. He is a member in the institution of engineering and technology (IET). Dr. Raed also member in Centre of Research and Development of IoT (CREDIT), Asia Pacific University of Technology and Innovation (APU).

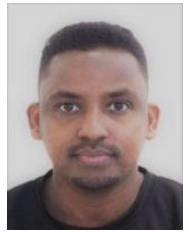

Aden Abdillahi has completed his high school in 2009 and joined Djibouti university faculty of accounting management. In year of 2012 started his Bachelor degree of Telecommunication Engineering at Asia Pacific University and Currently pursuing his master of Data Science and Business Analytics. 


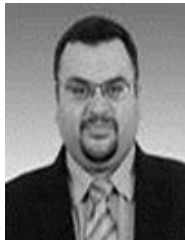

Dr. Maythem Kamal Abbas Al-Adili was born in Baghdad, Iraq, in 1984. He got his BSc in Control and Computer Systems Engineering from University of Technology in Baghdad, Iraq in 2005. In 2014, he was granted his $\mathrm{PhD}$ in Electrical and Electronic Engineering from Universiti Teknologi Petronas. Since 2008 till 2014, he served as a researcher with the Information Technology Department and the Electrical and Electronics Engineering department in Universiti Teknologi Petronas. He is the author of several journal articles and conference papers those were published in several countries. His research interests include Internet of Things (IoT), vehicular ad hoc networks (VANET), formal specification languages, decision making algorithms, protocol design, intelligent systems and robotics. He served as a reviewer and as a technical programme committee in many international conferences and journals. Currently, Dr. Maythem is a full time lecturer in Asia Pacific University (APU) and an active researcher in several research centers. 